\title{
Effect of Backward Design With Virtual Learning Ecosystem to Enhance Design Thinking and Innovation Skills
}

\author{
Chananchida Chunpungsuk ${ }^{1}$, Pinanta Chatwattana ${ }^{1} \&$ Pallop Piriyasurawong ${ }^{1}$ \\ ${ }^{1}$ King Mongkut's University of Technology North Bangkok, Bangkok, Thailand \\ Correspondence: Chananchida Chunpungsuk, King Mongkut's University of Technology North Bangkok, Bangkok, \\ Thailand. Tel: 66-863-810-765. E-mail: aoraee_6908@msn.com
}

Received: July 10, 2021

Accepted: August 12, 2021

Online Published: September 26, 2021

doi:10.5430/rwe.v12n4p70

URL: https://doi.org/10.5430/rwe.v12n4p70

\begin{abstract}
The backward design with virtual learning ecosystem aims to enhance design and innovative ideas as an application that simulates a virtual learning environment where students can interact with the simulated environment using their smartphones and digital goggles. This approach allows continuous, limitless self-learning based on cloud computing and social network, a guideline for the 21 st century skill training that focuses on the learner, and enhance design and innovative ideas. This research aims were to (1) develop a backward design with virtual learning ecosystem to enhance design thinking and innovation skills, (2) study posttest learning achievement after application of the backward design with virtual learning ecosystem to enhance design thinking and innovation skill, (3) study design thinking skills assessment of students after using the backward design with virtual learning ecosystem to enhance design thinking and innovation skills, and (4) study posttest innovation of students after using backward design with virtual learning ecosystem to enhance design thinking and innovation skills. The sample group in this study is divided into 2 groups, i.e., (1) the seven experts in design and development of information technology media and technology digital media selected from various educational institutes, and (2) the 20 undergraduates from Digital Media Technology Program, Faculty of Industrial Technology, Muban Chombueng Rajabhat University currently enrolled in the DMT60711 Development of Mobile Application course.
\end{abstract}

Keywords: backward design, virtual learning ecosystem, virtual learning environment, design thinking, innovation

\section{Introduction}

In the 21st century, computer has been developed enough for easy use. One direction of such development is the "anytime, anywhere" environment that allows use of computer regardless of physical location (Sentence et al, 2017). Education of the 21st century emphasizes learner skill training, one of the key skills of the future for professional careers (Baker, 2014). This enhances a learning society. Still, in order to create such the society where everyone has an opportunity for lifetime learning, suitable tools, learning sources, and network must be developed and accessible from as far as possible, so that everyone can get education with flexibility. Education of today needs change in methods and tools to suit the modern times and circumstances of the learners (Pragathi \& Sonar, 2013). In the current time, social media is a main tool for communication and information exchange between man and computer, in order to support communication on social media. Social Cloud-based learning is combination of social network and cloud computing for certain activities (Chard, Bubendorfer, Caton \& Rana, 2012).

Backward design process, brought up by Wiggins \& McTighe (2006) bases on the principle of "think from the start to the end", then starts from the end product (target or standard of learning), which comes from the curriculum, as evidence of learning or performance. This is called learning standard. Then, a plan is formulated to teach necessary knowledge in order to achieve the end product. In this step, the planning process must be related and connected.

Currently, technological advancements allow the use of virtual reality in education. The word "Virtual Reality" means a technology that allows the user to interact with a simulated environment created by computers (Burdea, \& Coiffet, 2003). The simulated environment might be based on the real world or totally imaginary. Interaction with the simulated environment in the manner similar with the real world could be created by using tools that allow the user to behave in the virtual world (Laowreandee, Kitroongrueng \& Sirisamphan, 2017). This is a guideline for 21st century skill training that focuses on the learner, and promotes design thinking and innovation skills (Partnership for 21 st Century Skills). This is a learner development guideline for the 21 st century that focuses on self-learning, 
creativity and innovation.

From the aforementioned background and importance, it can be concluded that the use of learning environment focused on cost-effectiveness and realism, based on cloud computing and social media, would allow the learner to access the content through virtual reality, and enhance limitless self-learning and innovation that is useful for the community.

\section{Literature Review}

\subsection{Backward Design}

Backward design process, brought up by Wiggins \& McTighe (2006) bases on the principle of "think from the start to the end", then starts from the end product (target or standard of learning), which comes from the curriculum, as evidence of learning or performance. This is called learning standard. Then, a plan is formulated to teach necessary knowledge in order to achieve the end product. In this step, the planning process must be related and connected summarized in a three-step process:

- Identify the desired objective: The standard analysis of content and it was prepared. Retentive knowledge and proficiency are important for identifying the desired objective. Thus, each learning unit should be analyzed to get a clear picture of which retentive knowledge to be implanted into the student. This process has to be systematic 1) stimulate the original knowledge to create familiarity with the new knowledge, 2) enchance the critical knowledge and skills to improve new knowledge, 3) connect the knowledge to form retentive knowledge and proficiency.

- Identify acceptable evidence: There is evidence that shows the comprehensions and skills of students that it was accepted. The backward design learning indicates a guideline for the teacher to build assessment evidence. Wiggins and McTighe (2006) defined five behaviors that expressed knowledge, proficiency and feeling, 1) ability to explain things in an easy manner, 2) ability to translate mearnings in specific contexts, 3) ability to apply knowledge or process to different situations, 4) ability to connect important issues or solve problems rationally, and 5) having own knowledge and understanding.

- Plan learning experiences and instruction: When given evidence what shows appropriately comprehension. Next, think about teaching activities such as knowledge, practice, and attitude. These evidences will be used for consideration about which item the learner has to learn with effectiveness, and which item that has to be taught and guided, for example.

Table 1. The synthesis of the backward design process

\begin{tabular}{|c|c|c|c|c|c|c|}
\hline Backward design process & 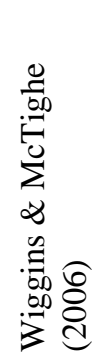 & 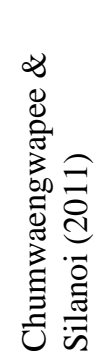 & 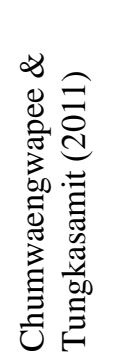 & 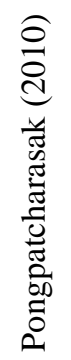 & 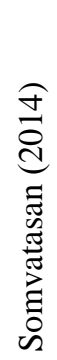 & 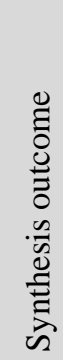 \\
\hline Definition of problem & & & $\sqrt{ }$ & & $\checkmark$ & $\checkmark$ \\
\hline Identify desired goals & $\checkmark$ & $\checkmark$ & $\checkmark$ & $\checkmark$ & $\checkmark$ & $\checkmark$ \\
\hline Determine acceptable evidence & $\checkmark$ & & & $\checkmark$ & & $\checkmark$ \\
\hline Experience learning & $\checkmark$ & & $\checkmark$ & $\checkmark$ & $\checkmark$ & $\checkmark$ \\
\hline Problem solving & & $\checkmark$ & $\checkmark$ & & & \\
\hline Evaluation & & & & & $\checkmark$ & $\checkmark$ \\
\hline
\end{tabular}

From Table 1, the researcher examined papers and research works related with backward design process using virtual learning environment to promote design and innovation thinking, and thus five steps could be synthesized (1) Definition of problem (2) Identify desired goals (3) Determine acceptable evidence (4) Experience learning and (5) Evaluation. 


\subsection{Virtual Reality}

Virtual reality is a group of computer technologies that construct and work on a control system in the virtual environment with a computer system to makes users feel like they are using their life in an environment created and be like seeing with their eyes and have accessories for touch such as masks, touch gloves, etc. Weennasusoprasit (2005) gave the meaning about Virtual Reality that it is the evolution from science and research that called Haptic. Haptic is a science that relates to feelings. And it was received from human touches such as images, sounds, and other elements, to make humans feel like, they are being in a real environment and can able to interact with that environment. The environment is a program in a computer that was simulated in advance. And that was called a virtual environment to makes a virtual feeling that consist of 3 elements as follows. For the first element is human or user. Next, the second component is a device or device to make a feeling that we call Haptic Interfaces. Finally, the last component is a virtual environment that needs to be simulated.

The virtual reality system is an application that can generate a 3D virtual environment where the user can interact with multiple interfaces such as voice command, audio, touch, or free camera. Vergara, Rubio \& Lorenzo (2017) categorized VR (Virtual Reality System) into to types according to interaction and equipment.

- Non-immersive or Desktop VR or Window on World System (WoW) uses normal monitor in displaying the virtual environment.

- Immersive VR which uses a head-mounted display that can provide audio and video, along with other equipment such as conventional peripherals (Like keyboard or mouse) or specific devices (consoles).

In this study, the author uses the Immersive VR system for development because the learner can interact with the virtual environment with their head-mounted display.

\subsection{Virtual Learning Ecosystem}

The idea of a learning ecosystem as a metaphor holds promise as a holistic framework for representing the multiplicity of interrelationships and entanglements of learners and teachers, stakeholders, and learning technologies and e-learning materials (Washington, 2015). The main purpose and function of the virtual learning ecosystem is to enable dynamic relationships and interactions between humans and digital content, and information flow, knowledge transfer and transformation, as shown in Figure 1.

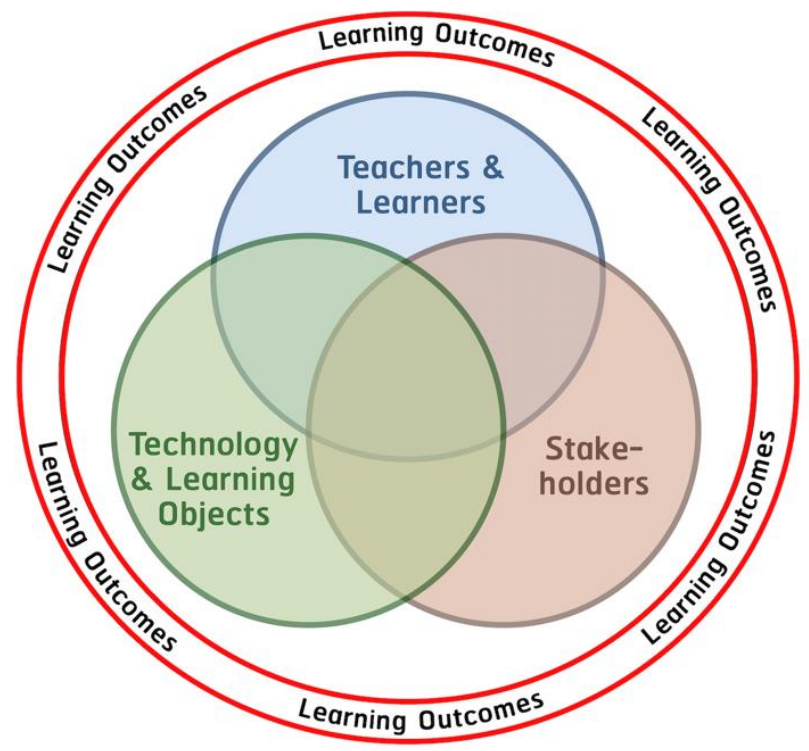

Figure 1. Virtual Learning Ecosystem (Washington, 2015)

\subsection{Design Thinking}

Design thinking should consist of understanding, integrated thinking, optimism, experience, and work cooperation. 
And for the design thinker should have a variety of important property as follow: learning properties, Management features, and properties for creating. Brown (2008) found that design thinking is a method that stimulates various ideas what is the origin of the development for new things or what is we call innovation by use on Human-Centered Design. Design thinking is the thighs that pass on the thoughts, feelings, and methods that combine works with people's needs by choosing the appropriate technology and marketing. Moreover, Brown believes that design thinking will be very beneficial to the business world in the present due to management ideas and the best instruction are open and free.

Table 2. The synthesis of the design thinking

\begin{tabular}{|c|c|c|c|c|c|c|}
\hline Step of design thinking & 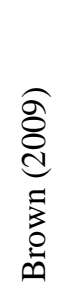 & 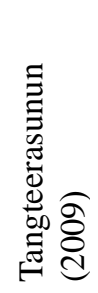 & 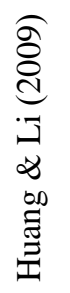 & 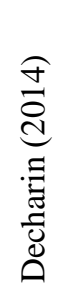 & 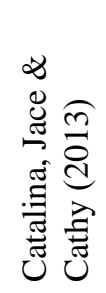 & 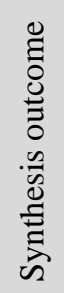 \\
\hline Understanding & $\checkmark$ & $\checkmark$ & $\checkmark$ & $\checkmark$ & $\checkmark$ & $\checkmark$ \\
\hline New define & $\checkmark$ & $\checkmark$ & $\checkmark$ & $\checkmark$ & $\checkmark$ & $\checkmark$ \\
\hline Ideate & $\checkmark$ & & & & $\checkmark$ & $\checkmark$ \\
\hline Design & $\checkmark$ & $\checkmark$ & $\checkmark$ & $\checkmark$ & $\checkmark$ & $\checkmark$ \\
\hline Prototype & $\checkmark$ & & & & & $\checkmark$ \\
\hline Test & & $\checkmark$ & $\checkmark$ & $\checkmark$ & $\checkmark$ & $\checkmark$ \\
\hline
\end{tabular}

From Table 2, six steps can be synthesized for the design thinking process: (1) Understanding (2) New define (3) Ideate (4) Design (5) Prototype and (6) Test. In this research, the author also studied result from the assessment of thinking and innovation skills.

\subsection{Innovation}

National Innovation Agency (2005) gives the meaning of innovation as "New things that originate from knowledge's using and creativity that is beneficial to the economy and society". And sometimes innovation means something that originate from the ability to use knowledge, creativity, skills and technology experience or management to develop products, production process, new service to respond the needs of the market demand or adjust technology, technology extension, Product design, and training that use to increase economic value and create a public advantage in the pattern of business, investment, entrepreneur or new market or new source of income new employment.

Chatwattana (2021) mentioned three components of innovation:

1. Newness, as innovation should have. Newness means a new thing, which could be product, service or process that can be either an improvement of existing product, service or process, or an entirely new thing.

2. Economic and social benefits, which include commercial benefit or success. Innovation must be able to increase value through development of new things. Benefit in this case may be financial (can be measured in terms of monetary value) or social, which cannot be measured.

3. Knowledge and creativity idea. In this case, an innovation must be based on the use of knowledge and creativity instead of reproduction or copying. 
Table 3. The synthesis of innovation

\begin{tabular}{|c|c|c|c|c|c|c|}
\hline Characteristic & 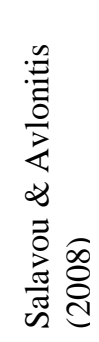 & 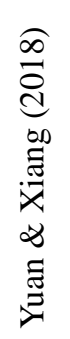 & 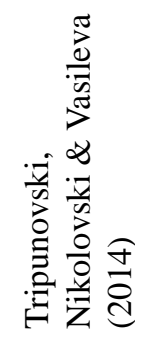 & 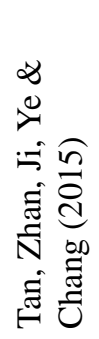 & 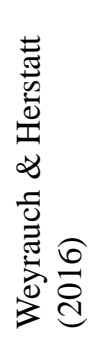 & 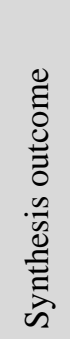 \\
\hline Novelty and uniqueness & $\checkmark$ & $\checkmark$ & $\checkmark$ & $\checkmark$ & $\checkmark$ & $\checkmark$ \\
\hline Objective & $\checkmark$ & $\checkmark$ & $\checkmark$ & & $\checkmark$ & $\checkmark$ \\
\hline Efficiency & $\checkmark$ & $\checkmark$ & $\checkmark$ & $\checkmark$ & $\checkmark$ & $\checkmark$ \\
\hline Possibility & $\checkmark$ & $\checkmark$ & $\checkmark$ & $\checkmark$ & $\checkmark$ & $\checkmark$ \\
\hline Design & & & & $\checkmark$ & & \\
\hline Ease of use & & & & & $\checkmark$ & \\
\hline Cost & & & $\checkmark$ & & $\checkmark$ & $\checkmark$ \\
\hline Modern technology & $\checkmark$ & & & & & \\
\hline
\end{tabular}

From Table 3, six characteristics of innovative research can be synthesized as follows: (1) Novelty and Uniqueness (2) Objective (3) Efficiency (4) Possibility and (5) Cost. In this work, the researcher also assess posttest innovativeness of students after participating in the backward design with virtual learning ecosystem to promote thinking and innovation skills.

\section{Research Objectives and Hypotheses}

The objectives of this research were to:

- Develop a backward design with virtual learning ecosystem to enhance design thinking and innovation skills.

- Study posttest learning achievement after application of the backward design with virtual learning ecosystem to enhance design thinking and innovation skills.

- Study design thinking skills assessment of students after using the backward design with virtual learning ecosystem to promote thinking and innovation skills.

- Study posttest innovation of students after using backward design with virtual learning ecosystem to enhance design thinking and innovation skills.

Research hypotheses were study of the developed system, and formed as follows:

- The backward design with virtual learning ecosystem to enhance design thinking and innovation skills has high quality.

- Students using the backward design with virtual learning ecosystem to enhance design thinking and innovation skills will have higher posttest learning achievement than pretest achievement with statistical significance of .05 .

- After the backward design with virtual learning ecosystem to enhance thinking and innovation skills, assessment result of design thinking skills shall be high.

- After the backward design with virtual learning ecosystem to enhance thinking and innovation skills, assessment result of innovation shall be higher than the $70 \%$ criteria.

\section{Research Methodology}

\subsection{Sample Group}

The sample group of this research, derived from purposive sampling, is divided into 2 groups, i.e., (1) the seven experts in design and development of information technology media and technology digital media selected from various educational institutes, and (2) the 20 undergraduates from Digital Media Technology Program, Faculty of 
Industrial Technology, Muban Chombueng Rajabhat University currently enrolled in the DMT60711 Development of Mobile Application course.

\subsection{Data Collection and Analysis}

In the development of the backward design with virtual learning ecosystem to enhance design thinking and innovation skills, the researchers have developed and employed the following data collecting tools, i.e., (1) backward design with virtual learning ecosystem to enhance design thinking and innovation skills, (2) quality evaluation form of the backward design with virtual learning ecosystem to enhance thinking and innovation skills, (3) evaluation form of the learning achievement before and after learning the backward design with virtual learning ecosystem to enhance design thinking and innovation skills, (4) evaluation form of the design thinking skills by the students after learning the backward design with virtual learning ecosystem to enhance design thinking and innovation skills, and (5) evaluation form of the innovation by the students after learning the backward design with virtual learning ecosystem to enhance design thinking and innovation skills. The statistics used to analyze the data consists of mean, standard deviation and t-test.

\subsection{Methodology}

This study aimed to examine the use of backward design with virtual learning ecosystem to enhance design thinking and innovation skills. The research method was divided into two phases:

Phase 1: Development of the backward design with virtual learning ecosystem to enhance design thinking and innovation.

The backward design with virtual learning ecosystem to enhance design thinking and innovation skills consisted of behavioral objective, content, learning management plan, virtual learning ecosystem, learning achievement assessment form, design thinking skills assessment form, and innovation assessment form. All of which were learning support tools for the sample group. Research tools in this phase were the quality assessment form (for the proposed virtual ecosystem), learning achievement assessment form, design thinking skills assessment form and innovation assessment form.

Phase 2: Result study after the use of the backward design with virtual learning ecosystem to enhance design thinking and innovation skills. This phase aimed to:

- Compare pretest and posttest learning achievement before and after the use of backward design with virtual learning ecosystem.

- Assess design thinking skills after the backward design with virtual learning ecosystem.

Criteria for design thinking skills assessment used the 4-level rating scale, definition of which is shown in Table 4.

Table 4. Average score range and definition of design thinking skills assessment

\begin{tabular}{cl}
\hline Average score range & \multicolumn{1}{c}{ Interpretation } \\
\hline $11.26-15.00$ & High design thinking skills \\
$7.51-11.25$ & Moderate design thinking skills \\
$3.76-7.50$ & Low design thinking skills \\
$0.00-3.75$ & No design thinking skills \\
\hline
\end{tabular}

- Assess innovative after the use of backward design with virtual learning ecosystem.

Criteria for innovation assessment used the 4-level rating scale, definition of which is shown in Table 5.

Table 5. Average score range and definition of innovation assessment

\begin{tabular}{cl}
\hline Average score range & \multicolumn{1}{c}{ Interpretation } \\
\hline $13.51-18.00$ & High innovation \\
$9.01-13.50$ & Moderate innovation \\
$4.51-9.00$ & Low innovation \\
$0.00-4.50$ & No innovation \\
\hline
\end{tabular}




\section{Results and Discussion}

In order to make an assessment of the use of backward design with virtual learning ecosystem to enhance design thinking and innovation skills, the researcher used the backward design with virtual learning ecosystem on the sampled group (selected by cluster sampling), consisting of 20 undergraduates from Digital Media Technology Program, Faculty of Industrial Technology, Muban Chombueng Rajabhat University currently enrolled in the DMT60711 Development of Mobile Application course.

\subsection{Development Result of Backward Design With Virtual Learning Ecosystem to Enhance Design Thinking and Innovation Skills}

Development of the backward design with virtual learning ecosystem to enhance design thinking and innovation skills resulted in a smartphone application that uses digital goggles. The learner is required to install the developed application in their Android smartphones. When goggles are worn, the learner will be able to see the virtual environment, along with digital content and learning guide according to the backward design with virtual learning ecosystem to enhance design thinking and innovation skills.

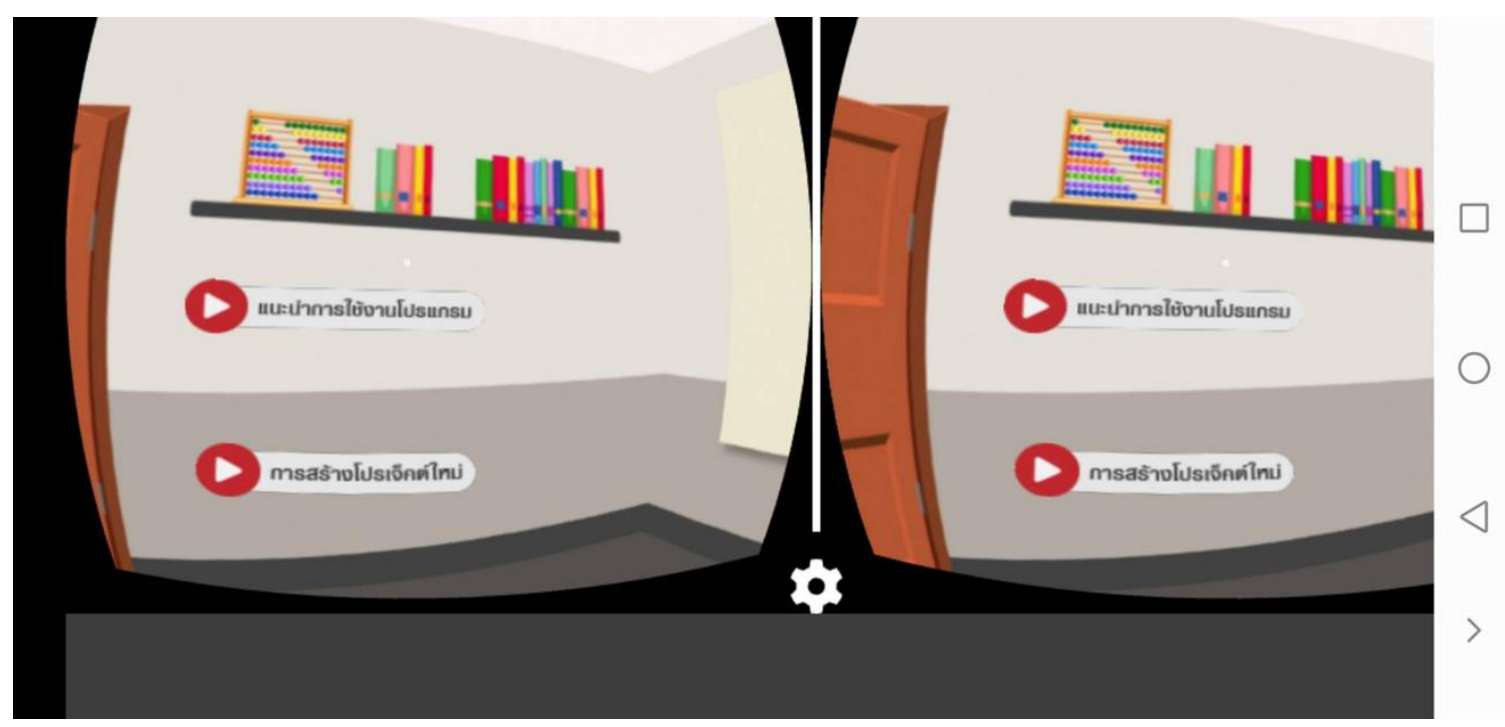

Figure 2. Virtual class lessons

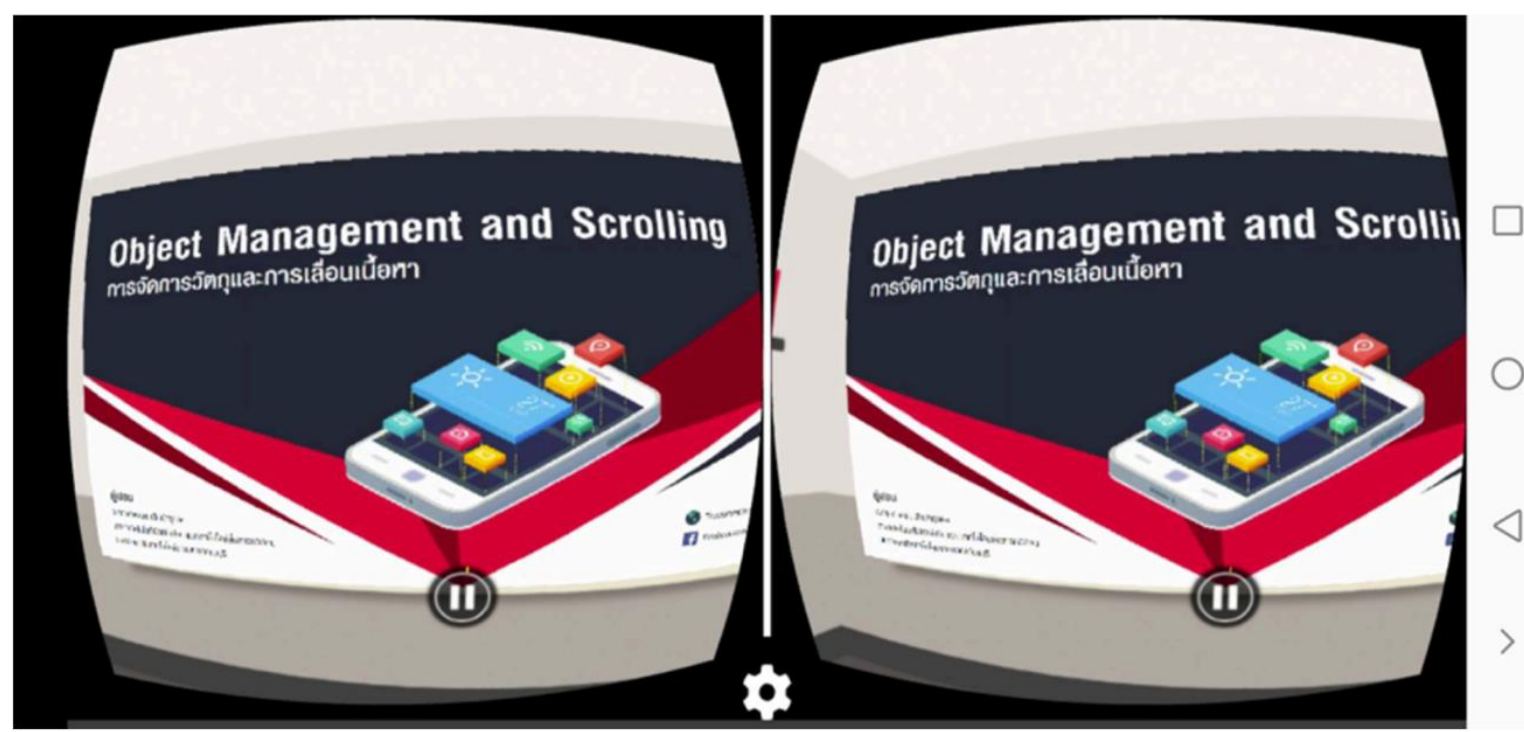

Figure 3. Virtual class lessons (Content) 
5.2 Results of the Quality Assessment of the Backward Design With Virtual Learning Ecosystem to Enhance Design Thinking and Innovation Skills

Quality assessment of the backward design with virtual learning ecosystem to enhance design thinking and innovation skills was done by seven experts in design and development of information technology media and technology digital media selected from various educational institutes. The researchers relied on the data analysis and interpretation criteria of Kanasutra (1995), as seen in Table 6.

Table 6. Average score range and interpretation of results

\begin{tabular}{cl}
\hline Average score range & \\
\hline $4.50-5.00$ & Highest level \\
$3.50-4.49$ & High level \\
$2.50-3.49$ & Average level \\
$1.50-2.49$ & Low level \\
$1.00-1.49$ & Very low level \\
\hline
\end{tabular}

The results of the quality assessment of the backward design with virtual learning ecosystem to enhance design thinking and innovation skills is shown in Table 7 and Table 8.

Table 7. Quality assessment of the backward design with virtual learning ecosystem to enhance design thinking and innovation skills (Content)

\begin{tabular}{|c|c|c|c|}
\hline \multirow{2}{*}{ Assessment } & \multicolumn{2}{|c|}{ Results } & \multirow{2}{*}{ Quality } \\
\hline & Mean & S.D. & \\
\hline 1. Content and presentation & 4.46 & 0.45 & High \\
\hline 2. Language and picture & 4.53 & 0.49 & Highest \\
\hline 3. Font and color & 4.52 & 0.50 & Highest \\
\hline $\begin{array}{l}\text { 4. Content suitability with learning activities in } \\
\text { backward design with virtual learning ecosystem }\end{array}$ & 4.57 & 0.37 & Highest \\
\hline Overall & 4.52 & 0.45 & Highest \\
\hline
\end{tabular}

Table 7 shows that quality assessment of the backward design with virtual learning ecosystem to enhance design thinking and innovation skills (Content) shows the highest rating (Mean=4.52, S.D.=0.45), concurring with the first hypothesis. Thus, it can be concluded that the proposed backward design with virtual learning ecosystem to enhance design thinking and innovation skills is workable and can enhance self-learning.

Table 8. Quality assessment of the backward design with virtual learning ecosystem to enhance design thinking and innovation skills (Learning design)

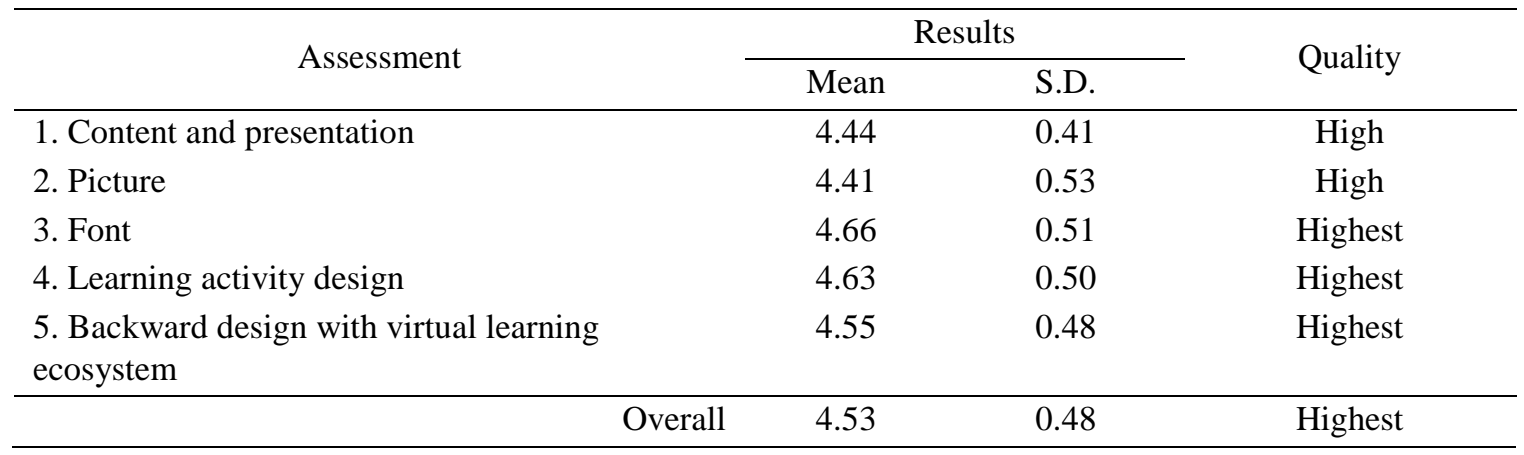


Table 8 shows that quality assessment of the virtual learning ecosystem to enhance design thinking and innovation skills (Learning design) shows the highest rating (Mean=4.53, S.D.=0.48), concurring with the first hypothesis. Thus, it can be concluded that the proposed virtual learning ecosystem to enhance design thinking and innovation skills is workable and can promote self-learning.

5.3 Comparison of Pretest and Posttest Learning Achievement Before and After the Use of the Backward Design With Virtual Learning Ecosystem to Enhance Design Thinking and Innovation Skills

Comparison of pretest and posttest learning achievement before and after the use of the backward design with virtual learning ecosystem to enhance design thinking and innovation skills was done by 20 undergraduates from Digital Media Technology Program, Faculty of Industrial Technology, Muban Chombueng Rajabhat University currently enrolled in the DMT60711 Development of Mobile Application course is shown in Table 9.

Table 9. Comparison of pretest and posttest learning achievement before and after the use of the backward design with virtual learning ecosystem to enhance design thinking and innovation skills

\begin{tabular}{lccccc}
\hline \multicolumn{1}{c}{ Testing } & Full score & Mean & S.D. & t-test & Sig. \\
\hline Pretest & 60 & 37.90 & 7.17 & 7.320 & $.00^{*}$ \\
Posttest & 60 & 51.60 & 5.33 & & \\
\hline
\end{tabular}

*Statistical significance is .05

Table 9 shows that comparison of pretest and posttest learning achievement before and after the use of the backward design with virtual learning ecosystem to enhance design thinking and innovation skills was done on a sample group, which consisted of 20 undergraduates from Digital Media Technology Program, Faculty of Industrial Technology, Muban Chombueng Rajabhat University. The comparison revealed the pretest score (Mean=37.90, S.D.=7.17) and posttest score (Mean=51.60, S.D.=5.33), and after the backward design with virtual learning ecosystem to enhance design thinking and innovation was applied the learning achievement improved with statistical significance of .05, concurring with the second hypothesis and Pakprod (2014) which found that virtual reality-based class could improve learning achievement, and Phewngam (2011), which found that backward design learning could also improve learning achievement.

5.4 Assessment of Design Thinking Skills After the Use Backward Design With Virtual Learning Ecosystem to Enhance Design Thinking and Innovation Skills

Assessment of design thinking skills after the use backward design with virtual learning ecosystem to enhance design thinking and innovation skills was based on individual performance, as shown in Table 10.

Table 10. Result of design thinking skills after the use backward design with virtual learning ecosystem to enhance design thinking and innovation skills

\begin{tabular}{ccccc}
\hline $\mathrm{N}$ & Full score & Mean & S.D. & Percentage \\
\hline 20 & 15 & 11.27 & 2.09 & 75.32 \\
\hline
\end{tabular}

From Table 10, design thinking skills assessment after the use of backward design with virtual learning ecosystem to enhance design thinking and innovation skills on 20 the sample group members revealed that posttest design skills (Mean=11.27, S.D. $=2.09$ ) or $75.32 \%$, which was rated high. This is consistent with the third hypothesis which showed that the use of the backward design with virtual learning ecosystem to enhance design thinking and innovation could improve design thinking skills, as the process emphasized on design skill training and was able to keep the learner engaged, in addition to allowing the learner to use their communication and IT skills. Marin, Hargis \& Cavanaugh (2013) found that challenge-based learning through smartphones would promote in-depth learning, experience sharing, new knowledge and improvement of the students. Johansson-Skolberg, Woodilla \& Çetinkaya (2013) found that if properly integrated, the design concept could improve and produce designs. Lloyd (2013) found that remote design learning would improve learning skills in the 21 st century. 
5.5 Assessment of Innovation After the Use Backward Design With Virtual Learning Ecosystem to Enhance Design Thinking and Innovation Skills

Assessment of innovation after the use backward design with virtual learning ecosystem to enhance design thinking and innovation skills was based on individual performance, as shown in Table 11.

Table 11. Result of innovation after the use backward design with virtual learning ecosystem to enhance design thinking and innovation skills

\begin{tabular}{ccccc}
\hline $\mathrm{N}$ & Full score & Mean & S.D. & Percentage \\
\hline 20 & 18 & 13.08 & 2.11 & 72.70 \\
\hline
\end{tabular}

From Table 11, innovation assessment after the use of backward design with virtual learning ecosystem to enhance design thinking and innovation skills on 20 the sample group members revealed that posttest design skills (Mean=13.08, S.D. $=2.11$ ) or $72.70 \%$, passing the $70 \%$ requirement. This agrees with the fourth hypothesis, showing that the use of the backward design with virtual learning ecosystem to enhance design thinking and innovation skills could improve innovation. Chatwattana, Kuntama \& Phadungthin (2020) found that the use of virtual reality for learning promotion could directly respond to the learners' experience by using the currently-available technology to create a learning society with instantaneous interaction and real-time tracking. This also concurs with Wästberg et al (2019).

\section{Conclusion}

The backward design with virtual learning ecosystem to enhance design thinking and innovation is an application that simulate a virtual environment to support learning, where the learner can access interact with the simulated environment with their smartphones and goggles. There are seven components in the backward design: behavioral objective, content, learning management plan, virtual learning ecosystem, learning achievement assessment form, design thinking skills assessment form, and innovation assessment form. The proposed support tool was used on 20 undergraduates from Digital Media Technology Program, Faculty of Industrial Technology, Muban Chombueng Rajabhat University.

Examination of the result of the use of backward design with virtual learning ecosystem to enhance design thinking and innovation skills showed that the proposed design could meet all four hypotheses proposed by the researchers, showing usefulness and practicality of the backward design with virtual learning ecosystem to enhance design thinking and innovation in the 21 st century.

This work may be used as a guideline for designing the backward design with virtual learning ecosystem that promotes learning through the virtual environment. This is done by applying the virtual reality system and virtual learning ecosystem together to instill design thinking and innovation skills that promotes self-development and learning society. The researcher also found limitations of this study and thus concluded both limitations and suggestions as a guideline for further development.

- During the backward design with virtual learning ecosystem to promote design thinking and innovation skills, there should be more activity diversity.

- There should be self-assessment criteria for the learner during the activity (at every step).

- There should be studies on other variables such as problem-solving skills, critical thinking and analytical skills.

- This work should be further improved for other classes to promote more application.

\section{References}

Baker, L. E. (2014). Learning and Assessment: Twenty-First Century Skills and Cognitive Readiness. New Teaching and Measuring Cognitive Readiness, 53-70. https://doi.org/10.1007/978-1-4614-7579-8_3

Brown, T. (2008, June). Desing Thinking. Harvard Business Review, 84-92.

Brown, T. (2009). Change by Design: How Design Thinking Transforms Organizations and Inspires Innovation. New York: Harper Business.

Burdea, C. G., \& Coiffet, P. (2003). Virtual Reality Technology. Boston: MIT Press. https://doi.org/10.1162/105474603322955950 
Catalina, M., Jace, H., \& Cathy, C. (2013). iPad Learning Ecosystem: Developing Challenge-Based Learning Using Design Thinking. Turkish Online Journal of Distance Education, 14(2), 22-34.

Chard, K., Bubendorfer, K., Caton, J. S., \& Rana, F. O. (2012). Social Cloud Computing: A Vision for Socially Motivated Resource Sharing. IEEE Transactions on Services Computing, 5(4), 551-563. https://doi.org/10.1109/TSC.2011.39

Chatwattana, P. (2021). Creative Educational Innovations based on Experiential Learning to enhance Education of Digital Learners. Industrial Education and Technology, 20(1), 82-90.

Chatwattana, P., Kitsanu, K., \& Phadungthin, R. (2020). A 3D-interactive virtual classroom with a virtual learning environment. World Transactions on Engineering and Technology Education, 18(4), 387-392.

Chumwaengwapee, A., \& Tungkasamit, A. (2011). The Effect of Backward Design Learnigh Unit Using Historical Mathodology on Critical Thinking for Mattayomsuksa IV Students. Journal of Education Graduate Studies Research Khon Kaen University, 5(1), 148-154.

Chumwaengwapee, P., \& Silanoi, L. (2011). The Development of Backward Design on "Happy life with Sufficient Economic" by using Open Approach for Prathomsueksa 5 Students at Demonstation School of Khon Kaen University. Journal of Education Graduate Studies Research Khon Kaen University, 5(1), 101-109.

Decharin, P. (2014). Design Thinking. Retrieved from https://www.bangkokbiznews.com/blog/detail/591915

Huang, W. J., \& Li, H. Y. (2009). The mediating effect of knowledge management on social interaction and innovation performance. International Journal of Manpower, 30(3), 285-301. https://doi.org/10.1108/01437720910956772

Johansson-Skolberg, U., Woodilla, J., \& Çetinkaya, M. (2013). Design Thinking: Past, Present and Possible Futures. Creativity and Innovation Management, 22(2), 121-146. https://doi.org/10.1111/caim.12023

Kanasutra, P. (1995). Statistics for Research in the Behavioral Sciences. Bangkok: Chulalongkorn University Press.

Laowreandee, W., Kitroongrueng, P., \& Sirisamphan, O. (2017). Active learning instructional strategies for thinking development and educational improvement of the 21 st century. Nakhon Pathom: Phetkasem Printing Group.

Lloyd, P. (2013). Embedded Creativity: Teaching Design Thinking Via Distance Education. International Journal of Technology and Design Education, 23(3), 749-765. https://doi.org/10.1007/s10798-012-9214-8

Marin, C., Hargis, J., \& Cavanaugh, C. (2013). iPad Learning Ecosystem: Developing Challenge-Based Learning Using Design Thinking. Turkish Online Journal of Distance Education, 14(2), 22-34.

National Innovation Agency. (2005). Top Thai Innovation. Bangkok: National Innovation Agency, Ministry of Science and Technology.

Pakprod, N. (2014). Interactive Instructional Model Using Augmented Reality based on Edutainment to Enhance Emotional Quotient. Degree of Doctor of Philosophy Program in Information and Communication Technology for Education, King Mongkut's University of Technology North Bangkok. https://doi.org/10.5121/ijite.2013.2405

Partnership for 21st Century Skills. Framework for 21st Century Learning. Retrieved from http://www.p21.org/storage/documents/docs/P21_framework_0816.pdf

Phewngam, N. (2011). A study of the achievement and ability of concept thinking in Thai of Mathayomsuksa III students by Backward Design and the Teachers Manual. Master of Education Degree in Secondary Education, Srinakharinwirot University.

Pongpatcharasak, B. (2010). A Study of Learning Achievement and Ability in Solving Problem in Social Studies of Mathayomsuksa 5 Student by Backward Design. Master of Education degree in Secondary Education, Srinakharinwirot University.

Pragathi, M., \& Sonar, P. (2013). Goesmart Social Media Education Using Cloud Computing. International Journal of Engineering Research \& Technology, 2(9), 2236-2250.

Salavou, H., \& Avlonitis, J.G. (2008). Product innovativeness and performance: A focus on SMEs. Management Decision, 46(7), 969-985. https://doi.org/10.1108/00251740810890168

Sentance, S., Waite, J., Hodges, S., MacLeod, E., \& Yeomans, L. (2017). “Creating Cool Stuff”: Pupils' Experience of the BBC micro:bit. Proceedings of the 2017 ACM SIGCSE Technical Symposium on Computer Science 
Education, 531-536. https://doi.org/10.1145/3017680.3017749

Somvatasan, K. (2014). A study of English reading comprehension achievement of Matthayomsuksal students by using backward design planning. Master of Arts Degree in Applied Linguistics-English for Science and Technology, King Mongkut's Institute of Technology Ladkrabang.

Tan, H. K., Zhan, Z. Y., Ji, G., Ye, F., \& Chang, C. (2015). Harvesting big data to enhance supply chain innovation capabilities: An analytic infrastructure based on deduction graph. International Journal of Production Economics, 165, 223-233. https://doi.org/10.1016/j.ijpe.2014.12.034

Tangteerasunun, P. (2009). Innovative design towards the creative economy. Bangkok.

Tripunovski, A., Nikolovski, A., \& Vasileva, A. (2014). Creating innovation and development of a new product (managing innovations). Forum Scientiae Oeconomia, 2(3), 73-82.

Vergara, D., Rubio, P. M., \& Lorenzo, M. (2017). On the Design of Virtual Reality Learning Environments in Engineering. Multimodal Technologies and Interact, 1(11), 3-12. https://doi.org/10.3390/mti1020011

Washington, C. (2015). Virtual Learning Ecosystems: A proposed framework for integrating educational games, e-learning methods, and virtual community platforms. Retrieved from https://files.eric.ed.gov/fulltext/ED560265.pdf

Wästberg, S. B., Eriksson, T., Karlsson, G., Sunnerstam, M., Axelsson, M., \& Billger, M. (2019). Design considerations for virtual laboratories: A comparative study of two virtual laboratories for learning about gas solubility and colour appearance. Education and Information Technologies, 24, 2059-2080. https://doi.org/10.1007/s10639-018-09857-0

Weennasusoprasit, W. (2005). Development of CVT equipment for virtual reality-building systems. Bangkok: Department of Mechanical Engineering Chulalongkorn University.

Weyrauch, T., \& Herstatt, C. (2016). What is frugal innovation? Three defining criteria. Journal of Frugal Innovation, 2(1), 1-17. https://doi.org/10.1186/s40669-016-0005-y

Wiggins, G., \& McTighe, J. (2006). Understanding by Design. New Jersey: Prentice Hall.

Yuan, B., \& Xiang, Q. (2018). Environmental regulation, industrial innovation and green development of Chinese manufacturing: Based on an extended CDM model. Journal of Cleaner Production, 176, 895-908. https://doi.org/10.1016/j.jclepro.2017.12.034

\section{Copyrights}

Copyright for this article is retained by the author(s), with first publication rights granted to the journal.

This is an open-access article distributed under the terms and conditions of the Creative Commons Attribution license (http://creativecommons.org/licenses/by/4.0/). 